\title{
LOS GUARANÍ Y LOS CHANÉ EN EL AHORA. CHAMANISMO, RELIGIÓN Y ETNOPOLÍTICA EN EL NOROESTE ARGENTINO
}

\author{
THE GUARANÍ AND THE CHANÉ IN \\ THE NOW. SHAMANISM, RELIGION \\ AND POLITICS IN NORTHWESTERN \\ ARGENTINA
}

PhD Maria Eugenia Flores

pankraleon@gmail.com

Instituto de Investigaciones en Humanidades y Ciencias Sociales

Consejo de Investigación Universidad Nacional de Salta, Argentina

(ICSOH-CONICET-CIUNSa)

ORCID: https://orcid.org/0000-0003-3419-4731

\section{RESUMEN}

El objetivo del presente artículo es indagar sobre el pasado y el presente de los líderes religiosos guaraní y chané en el territorio del actual Norte Argentino. Por un lado, se indagará sobre lo que fue el sistema chamánico del complejo chiriguano-chané, descrito en estudios etnohistóricos, y, por otro lado, se pretende analizar los procesos de yuxtaposición de estos sistemas chamánicos con los sistemas religiosos cristianos, trayendo a colación algunos casos etnográficos actuales de líderes políticos y religiosos indígenas y evangélicos, que manejan las artes de la curación. Por último, se presentará un análisis sobre las emergencias espirituales, las mediaciones culturales y las transfiguraciones religiosas entre los pueblos amerindios contemporáneos.

Palabras claves: Chamanismo. Guaraní chané. Etnopolítica. Emergencias espirituales.

\begin{abstract}
In this article we want to investigate the past and present of the Guarani and Chane religious leaders in the territory of current Argentine Northern. On the one hand, we will inquire about what the shamanic system of the Chiriguano-Chané complex described in ethnohistoric studies was, and, on the other hand, we intend to analyze the juxtaposition processes of these shamanic systems with the Christian religious systems, bringing up some ethnographic cases current of indigenous and evangelical political and religious leaders, who handle the arts of healing. Finally, an analysis is presented on spiritual emergencies, cultural mediations and religious transfigurations among contemporary Amerindian peoples.
\end{abstract}

Keywords: Shamanism. Guaraní chané. Ethnopolitics. Spiritual emergencies. 


\section{INTRODUCCIÓN}

El artículo está dividido en tres apartados. El primero, en el que se presenta un análisis de la etnohistoria, en base a los estudios sobre chamanismo y espiritualidad guaraní y chané, como los trabajos de Idogaya Molina (1978), Riester (1986, 1998), Bossert (2000), Combés (2005), Villar (2007-2011), Villavicencio Matienzo (2009), que dan un panorama de los procesos vividos por los pueblos del Chaco boliviano y argentino como los de la familia lingüística tupi guaraní.

En el siguiente apartado, se presenta un análisis sobre la emergencia de nuevas espiritualidades entorno a las religiones cristianas, devenidas de las misiones evangélicas asentadas en el umbral al Chaco. Para ello, se dialogara con las investigaciones sobre las misiones evangélicas con: Ceriani Cernadas (2017), Espinoza (2017), Pérez Bugallo (2017). Por último, se reflexiona sobre la realidad actual de las configuraciones etnopolíticas y religiosas de los pueblos guaraní-chané en el umbral al chaco americano, teniendo en cuenta las emergencias simbólicas y las articulaciones entre los agentes sociales: curador/curado, paye/paciente, pastor/creyente en las prácticas de salud y sanación espiritual.

\section{COMPLEJO CHIRIGUANO-CHANÉ EN LAS DESCRIPCIONES ETNOGRÁFICAS}

Las prácticas de cura de los pueblos originarios llamó siempre la atención de la antropología decimonónica, que vio en la figura del chaman, un personaje clave de la organización social y espiritual de los pueblos. Pero lo cierto es que, desde la llegada de los colonizadores y evangelizadores, hace más de quinientos años, las practicas chamánicas y de cura entre los pueblos indígenas americanos han sufrido dos cambios fundamentales. Uno es que, las prácticas llamadas chamánicas, han sido reducidas, desde la etnografía clásica a la medicina occidental, al complejo cura-atención que pone el énfasis en las diferentes dimensiones de las enfermedades, dejando de lado otros aspectos de las practicas chamánicas. Sin embargo, se ha comprobado que estas se relacionan con otros tipos de prácticas como las religiosas, económicas o políticas, donde la agencia del chamán se vincula a mecanismos de espiritualidad y a procesos políticos de construcción de la etnicidad (De Rose, 2013).

La etnohistoria y la antropología de principios del siglo XX, han dejado asentado en las descripciones realizadas de lo que se ha conocido y estudiado como categoría de análisis, como complejo chiriguano-chané. El autor Diego Villar (2007) propone que se rompa con esa categoría, que resulta para la actualidad, un concepto arcaico y exógeno a los pueblos que quieren describir. Con esta categoría se intentaba analizar los pueblos de diferentes trayectorias, pero con una historia en común. Según los etnógrafos, de principios del siglo xx, que recorrieron la región del Chaco Americano (Metraux, 1974), los chiriguano-chané serían el devenir de las migraciones preconquista, como la de los chané, de familia lingüística arawak, que vinieron desde los llanos de los mojos en la amazonia hacia el pedemonte o umbral al Chaco Americano, donde también llegaron los tupi, de la familia lingüística tupi guaraní.

Según los datos aportados por Villar (2007), se formó una población mixta en el umbral al Chaco Americano desde el Izoso, en Bolivia, hasta las yungas argentinas, en el noroeste, que no solo incluyó la presencia de los chiriguarnos y chanés, sino también, una variedad de grupos étnicos que comparten la lengua tupi guaraní como los izoseños, los simbas, los tapietes y los ava guaraní. 
Las familias arawak aportaron la densidad demográfica, las mujeres y la fuerza masculina de trabajo, las técnicas de alfarería, riego y tejido, el enmascaramiento ritual y las categorías de estratificación social. Por su parte, las familias tupi guaraní aportaron los mitos, el imaginário guerrero del keremba (guerrero) y el idioma (Villar, 2007:208). Estos núcleos poblacionales datan de 1530 y se pueden ubicar en las cumbres serranas fortificadas de Samaypata, en la actual Bolivia, que se mueven en dirección oeste y sur. Las familias dejaban sus malocas para establecerse sobre nuevos espacios. Los españoles designaron a este espacio como la Cordillera Chiriguana (Renard Csevitz et al, 1988:167). Estos espacios de relaciones interétnicas fueron homogenizadas de acuerdo a los etnógrafos y a los misioneros bajo el complejo chiriguano, que deja de lado la complejidad de las redes, alianzas, sometimientos y guerras interétnicas desatadas durante períodos coloniales, las cuales fueron paulatinamente transfiguradas por la presencia del blanco y especialmente, de las misiones en las tierras bajas de la llanura chaqueña. La historia oral de los chané, trabajada por Diego Villar (2007), manifiesta que las familias arawak chané, guaranizadas en su idioma, se asentaron en Argentina antes que las familias tupi guaraní (Villar, 2007:209).

Al respecto del chamanismo chiriguano, Alfred Metraux (1944) generaliza sobre el rol que cumplen las prácticas chamánicas en las sociedades que él conoció durante la primera mitad del siglo XX. Según el autor, "puede ser que en el corazón del chamanismo, los perturbados, los inestables o simplemente los meditativos encuentren una atmósfera propicia" (Metraux, 1944:198). El autor indaga un poco en la psicología de los chamanes, a los que considera con carácter fuerte, ya sea hombre paye o mujer paye (kuña paye), así mismo, destaca el carácter honesto de los mismos. Según el autor,

"los chamanes son muy escrupulosos en el ejercicio de su profesión. Solo en raras ocasiones se niegan a emprender una cura y, en las sesiones, se despiertan y trabajan con toda la energía de la que son capaces". (Metraux, 1944:199).

El antropólogo, Juergen Riester (1986), trabajó el chamanismo izoseño-guaraní, el cual define como:

\begin{abstract}
"una especialidad mágico-religiosa que se desarrolla en torno a un especialista, el chamán, que tiene poderes o cualidades especiales, como son el dominio de determinados espíritus o categorías de la naturaleza extra humana, con los cuales pueden comunicarse a través de un estado anímico, o sea, trance o vuelo mágico especialmente propiciado". (Riester, 1998:1031).
\end{abstract}

En su descripción del sistema chamánico, el autor aclara que el tema de la alteración de los estados de conciencia no es un elemento que se presente en muchas comunidades indígenas y chamanes, sino que, "existen especialistas que no se ponen en trance y sin embargo, diagnostican y curan enfermedades, encuentran cosas perdidas, se ponen en contacto con seres espirituales y controlan poderes trascendentales" (Riester, 1998:1031). Para el sistema chamánico chiriguano-chané, se menciona que es el ipaye, la figura del chamán, el que sustenta el conocimiento y las habilidades trascendentales, funcionando como médium entre los seres espirituales no humanos y los itinerarios de cura.

Según estos estudios etnohistóricos y etnográficos (Metraux, 1974; Riester, 1998; Combès, 2005), los ipaye reta se registraron para los chiriguanos, los izoseños y los chané (los grandes maestros chamanes), cuyo hacer es, todo lo que respecta a la salud indígena. Ellos demuestran conocimientos étnicos culturales como su formación a partir del aprendizaje y a partir del poder brindado por diferentes espíritus (alteridades no humanas). No existe una edad específica 
para el momento en que un hombre o una mujer es llamado/a por Mboi-Tumpa, es decir, por el eterno principio de la víbora. Según Riester:

\begin{abstract}
"Este espíritu tiene su morada en un cerro; tiene poder y facultad; es dueño de la sabiduría y en su frente tiene un poderoso espejo que le hace ver todas las cosas de la tierra y del cielo. Mboi-Tumpa está igualmente relacionado con la fertilidad de la tierra y del agua (agua tiene un especial significante en el Gran Chaco y simboliza en sí la fertilidad)". (Riester, 1986:266).
\end{abstract}

Para el caso del complejo chiriguano-chané, la serpiente es tomada como un ser con agencia social dentro del mundo que comparte el humano con diferentes tipos de seres. Sobre todo, para lo que se ha estudiado como el "sistema chamánico amazónico", que es compatible con el chaqueño, el símbolo de la serpiente es recurrente, dado a que ella es parte de la vida ritual de muchos pueblos indígenas y mestizos, tanto en Brasil, Bolivia, Perú, Ecuador, Colombia y Argentina. Este espíritu de la serpiente llama al hombre en sus sueños, y luego de una serie de ritos de paso, entrega al nuevo ipaye su poder, que se materializa en un espejo, con el que adquiere el poder de ver, considerar, tratar y estudiar las cosas en el pasado y ver las cosas futuras. Otro elemento que entrega esta alteridad no humana es la cruz, que en este caso, funciona como una alteridad que aconseja a los ipaye reta (Riester, 1986:266). También pueden ser formados por otros ipaye, en este caso el conocimiento y los saberes tradicionales se traspasan de uno hacia el otro. El o la ipaye maestro/a elige a su sucesor dentro de un grupo comunitario, y es común que el aprendiz sea una persona joven en comparación con el/la chamán. El maestro enseña a su discípulo -y esto durante varios años- hasta que el alumno tiene visiones propias y recibe en sus sueños las verdades.

Los saberes tradicionales se relacionan íntimamente con prácticas de cura que conocen los ipaye reta, y estas prácticas de cura se relacionan íntimamente con distintos seres o alteridades no humanas. Sea cual fuera la formación de los ipayes reta, ellos manifiestan relacionarse con los espíritus del agua (mboi-wuhu) y de la selva (ka-ija-reta). Igualmente aprenden a realizar "viajes celestiales", para visitar especialmente a los muertos, separando el alma de su cuerpo. En estos viajes, que se realizan durante el sueño, y son ayudados por diferentes categorías de animales que funcionan como alteridades no humanas (Riester, 1986; Flores, 2017). Estas relaciones intersubstanciales manifiestan epistemologías diferentes a las del occidente, y también ontologías propias del conocimiento de la naturaleza por parte de estos especialistas rituales.

Los chamanes paye e ipaye, que obtienen su poder heredado de un familiar, son los más poderosos entre los izoseños, ava guaraní y chané, aunque independientemente de la adquisición de su poder, todos ellos tienen jetepo, "la sustancia base del poder que el paye contiene en su cuerpo y le da las capacidades extraordinarias" (Riester, 1998:1034).

Entre los payes que obtienen su poder a través de un ser no humano, podemos mencionar que se registró para los izoseños-guaraní, a tres grandes espíritus o iyas, que trasmiten su poder al humano. Según Riester son tres: a) Mboivuju tüpa, o principio de la sirena que se encuentra en lagunas, playas y ríos; b) Mboi tüpa, o principio de la víbora que se encuentra en lugares tupidos del campo; y, c) Cuchi tüpa, o principio del cerdo que se encuentra en el monte y en la serranía. Estos especialistas que adquieren su poder, el jetepo, deben de tomar alcohol para su trabajo chamánico, para purificarse y reforzar su poder (Riester, 1998:1039). Al igual que los azande, descritos por Evans Pritchard (1976), el poder del chaman o brujo reside dentro de su cuerpo, pues el jetepo es la base de sus capacidades de cura y sus conocimientos de lo transdimensional. 
Los payes o ipaye fueron clasificados por la antropología cultural como "chamán", apenas por sus atributos de curandero de una tribu, literalmente "el que cura", pero el análisis del autor Villavicencio Matienzo (2009) indican que la palabra:

"paye está más próxima a la idea de un especialista en la palabra en el discernimiento entre el bien y el mal, haciendo uso de su poder de esclarecimiento por la sabiduría... sería como un consultor permanente y curador de la memoria guaraní que conoce todos los aspectos de esa realidad, aborda desde aspectos positivos y técnico-operacionales, hasta los aspectos más profundos acerca del comportamiento humano, de la ética y el sentido de humanidad. Los paye tienen un sentido de agregación social entorno a una visión estructurada del ser humano". (Villavicencio Matienzo, 2009:188).

La contraparte del chamán bueno (positivo para la vida en comunidad) fue el imbaekua, según Riester (1986:9), lo malo que se mueve en esta tierra es la fuerza negativa del mbaekua y se manifiesta en la persona del imbaekua. Ambos son personajes importantes en sus comunidades.

\section{LA TRANSFIGURACIÓN DEL PAYE}

La transfiguración étnica y cultural, por ende también la transfiguración religiosa, hace referencia a la reconfiguración de las matrices o formas religiosas y espirituales existentes en el momento del contacto, hasta desarrollar nuevas configuraciones sociales en los procesos de colonización y de formación de los estados nacionales, que recuerdan, sin reproducir linealmente, aquel pasado (Bartolome, 2008). El paye fue categorizado por muchos misioneros asentados en el Chaco y en el umbral al Chaco, formando misiones o reducciones de indígenas, como aliado del mal y contrario a los intereses de los misioneros, quienes tenían la misión de evangelizar y de reclutar mano de obra como parte del proceso civilizatorio llevado a cabo en la región.

Los misioneros jesuitas dejaron registradas las prácticas chamánicas llevadas adelante por personajes que ellos definieron como 'hechiceros', denotando una

"relación con el demonio y, probablemente, una asociación con las "brujas" europeas, de esta manera, se demonizaba una figura central de la sociedad indígena intentando desacreditarla para reducir su influencia”. (Rosso, 2012:169).

La evangelización como proceso civilizatorio requería que los indígenas renunciaran a muchas prácticas y creencias chamánicas. En su análisis de los escritos de los misioneros en el Gran Chaco Americano, Cintia Rosso (2012) identifica los procesos de diferenciación y etnificación de los pueblos de la región, entre los que se incluyen los pueblos asentados en el umbral al Chaco. La autora menciona que "en los escritos de los sacerdotes es clara la oposición entre los misioneros, quienes representaban la luz y la fe, y los chamanes, quienes personificaban las tinieblas y el error" (Rosso, 2012:170).

Teniendo en cuenta que las misiones se fundaron en el siglo XVII con las misiones jesuíticas primero, y luego con las franciscanas en el siglo XIX, y con las evangélicas en el siglo XX; se puede analizar la profundidad temporal de los cambios en la espiritualidad y/o religiosidad de estos pueblos asentados en el umbral al Chaco Americano. Estos cambios hicieron eco y modificaron la dinámica de la vida indígena, y amoldaron los intereses de la sociedad criolla 
o mestiza en un ámbito de conflicto y resignificación del mundo y la vida de los actores involucrados. Estos cambios tienen que ver con diversos procesos históricos, como las guerras interétnicas, las alianzas con los blancos, las migraciones y movimientos poblacionales, con la guerra del Chaco y el trabajo en los ingenios en el noroeste argentino llamado Mbaporenda (tierra de trabajo), con la evangelización a través del movimiento poblacional indígena hacia las misiones y los ingenios (Roso, 2012:166). Como bien lo analiza Roso (2012), el camino civilizatorio en las misiones se topó con los chamanes, que muchas veces jugaban el papel de líderes ante los despojos de la colonia (guerras, saqueos, genocidio), por lo que se convirtieron en enemigos de los misioneros.

Según Thierry Saignes, en su historia de los chiriguanos, los chamanes compiten directamente con los sacerdotes para "conocer el fin del mundo y el camino de la salvación" (Saignes, 2007:243). Es decir que, en estos episodios de enfrentamiento entre los sacerdotes y los chamanes, se evidencia la construcción de la etnicidad basada en la figura del chaman, que lucha por espacios de poder, acumulando potencia mágica frente a la evangelización y a los mandatos políticos. Al respecto, analiza Saignes que

"para los chiriguano (y sobre todo para los lideres), el recurso misionero aparece como la única vía de contrarrestar la seducción chamanica: permite conjurar la imposición de un poder ilimitado fundado en el terror de una palabra apocalíptica”. (Saignes, 2007:245).

El cristianismo se impone en las misiones como un nuevo orden social y moral, en estos contextos, las prácticas chamánicas heredadas de los antepasados y reactualizadas son un obstáculo. La función de las misiones chiriguanas del Chaco y del umbral al Chaco fue la de tutelar a los pueblos, sometiéndolos a un régimen colonial, junto con las estancias y los fortines, que funcionaron como fronteras civilizatorias. Sin embargo, la figura del sacerdote paulatinamente fue tomada como la de un paye. Al respecto, Saignes analiza que:

"El misionero deviene un prisionero de sus dobles obligaciones como jefe -generoso en palabras y bienes- y chaman -garantía mágica de la abundancia y la salvación”. (Saignes, 2007:269).

Estamos frente a un conflicto entre los actores involucrados dentro de un sistema chamánico, donde el propio chamán puede ser reemplazado de sus antiguas funciones dentro del grupo social. En este sentido, la presencia de las misiones y de la evangelización tuvieron su influencia en la transfiguración cultural de la figura del paye.

Cuando llegaron los misioneros a la región del actual noroeste argentino, a comienzos del siglo XX, el panorama religioso ya se mostraba complejo y concomitante a los procesos de desarrollo del capitalismo en la zona. Por ejemplo, se puede afirmar que la instalación de las misiones evangélicas en la región están íntimamente relacionadas al desarrollo de las industrias azucareras en distintos puntos del umbral al Chaco, donde los chiriguanos, ava guaraní, chanes, tapietes, wichis y otros pueblos, se asentaron en busca de trabajo.

Las misiones y las zafras fueron lugares propicios para el intercambio simbólico y material entre misioneros e indígenas, "un lugar privilegiado para la difusión y expansión de elementos de una nueva identidad indígena y evangélica" (Espinoza, 2017:203). Al tratarse de escenarios interculturales, allí se forjaron nuevos procesos de identificación y se manifestaron prácticas de construcción de una etnicidad política y evangélica. Interesante el planteo de Espinoza (2007) de tomar la zafra como una intersección y un ámbito privile- 
giado para la expansión del evangelismo entre los guaraní hablantes (Espinoza, 2017:203).

Las misiones católicas franciscanas estuvieron trabajando con los guaraníes (Pérez Bugallo, 2017), tanto del sur de Bolivia como del norte de Argentina. Instaladas en la Cordillera Chiriguana, también fueron una intersección, un espacio de negociación entre los sacerdotes y los chamanes. Estos procesos de misionalización, ya entrado en el siglo XX, demuestran que los indígenas de la zona ya estaban cristianizados, algunos católicos y otros evangélicos, quienes se refugiaban en las misiones también como parte de sus estrategias de supervivencia.

Los trabajos que se dedican a estudiar estos procesos de misionalización, en el contexto del noroeste argentino, no hacen mención de la presencia de los chamanes en las misiones franciscanas o evangélicas, aunque a través de la historia oral de algunos ancianos sabemos que coexistían, en el siglo XX, las practicas chamánicas dentro de las misiones, siendo los chamanes muchas veces bautizados en la fe cristiana. Estas nuevas reconfiguraciones de los roles y las categorías sociales fueron cambiando en función de hacer lo más llevadero posible los sufrimientos y despojos a los que fueron sometidos los pueblos indígenas en la colonia y en la república.

Por otro lado, está registrado que en las propias misiones, los chamanes mantenían la cultura de la palabra. Al respecto, Centurión Meneles analiza que

\begin{abstract}
"como alma y palabra son la misma cosa, al ser producto del contacto con los Dioses, son palabras verdaderas, por eso en el ritual del bautismo es donde el chamán, a través de la imposición del nombre del monte, que realiza la unión del niño con la naturaleza. En esta cultura centrada en la palabra, el chamán cumple un papel fundamental, al ser el elegido por los Dioses para a través de los sueños recibir las palabras sagradas que indican el camino verdadero, el camino de la perfección, aspiración ultima Ava-Katu-Ete”. (Centurión Meneles, 2013:121).
\end{abstract}

Incluso los chamanes podían, a partir de la transfiguración cultural de sus prácticas, realizar actos que solieran ser exclusivos de los sacerdotes, quienes al igual que los chamanes, tenían una oratoria evangelizadora que también los hacia dueños de la palabra. En este sentido, coincidimos con Villar (2007) cuando afirma que los sistemas chamánicos guaraní o chané no fueron hostiles al cambio cultural, sino abiertos, no dogmáticos, maleables e integradores. El autor plantea que "esta plasticidad le permite operar como un lenguaje ideal para el contacto multiétnico, un elemento de equilibrio que opera en las márgenes y en los puntos de contacto" (Villar, 2007:160).

El mismo autor afirma que, el sistema chamánico guaraní y el sistema chamánico chané, tienen o comparten conexiones significativas, como un universo de nociones y valores. Analiza también que, los chamanes chané

"eran percibidos como competidores en la carrera por los corazones, las almas y las mentes, sino que su mismo modo de vida constituía un escándalo moral - la remuneración que los enfermos les daban, por ejemplo, indignaba a los sacerdotes, quienes veían tras todo chamán a un embaucador, charlatán o estafador- Los religiosos tampoco admitían el carácter benéfico de ciertos chamanes, considerados enemigos de la evangelización — cuando no, en las versiones más exaltadas, aliados del mismo demonio-. Sin embargo, no es menos cierto que, al combatir a los especialistas nativos, los misioneros los reconocían, de algún modo, como iguales, y entonces reforzaban su prestigio". (Villar, 2007:163). 
Sin lugar a dudas, estos sistemas chamanicos, que pudieron ser catalogados como chiriguano chané, manifiestan una transfiguración religiosa, que no se abandona, pero que si se resignifica a través del uso de elementos y rezos católicos o evangélicos para aprender a manejar el poder de los otros, en este caso, de los sacerdotes, criollos e inclusive, de otros pueblos indígenas del Chaco como el poder de los chamanes wichí, que eran altamente valorados por los guaraní y los chané. Estas apropiaciones se combinan en una fuente ecléctica e intercultural como lo eran las misiones.

Los estudios de Idogaya Molina (1978) y Bossert (2000) sobre chamanismo guaraní-chané en la provincia de Salta, han demostrado que sus pautas y estados de salud dependen, en gran medida, de relaciones establecidas entre seres humanos y no humanos (almas de muertos, ancestros divinizados, espíritus de animales-chamánicos, etc.). Las experiencias y representaciones de este tipo de chamanismos, marca la relación con los muertos, en tanto, condición ontológica inacabada, a la vez, y relaciona la vida habitual de los vivos. Por otro lado, estos estudios del chamanismo guaraní-chané, exponen las diferentes esferas de la espiritualidad y la religiosidad guaraní: tipos, iniciaciones, terapias y ritos chamánicos de los paye; teofanías y personajes míticos (tumpas e Iyas); espacios cosmovisionales (ava y aña) y sus nociones de enfermedad, muerte y cura.

Los aportes de Villar (2007) permiten pensar en como la naturaleza y la cultura asientan una base cosmopolítica en su entorno, indivisible, generando prácticas de salud, conductas, sueños y demás vinculaciones (de género, usos permitidos del espacio, relaciones con la flora y fauna, etc.) entre las personas, el monte y las fuerzas espirituales que lo habitan.

Gran parte de estas comunidades guaraníes y chané (que incluye la variedad de grupos étnicos y lingüísticos) del noroeste argentino, migraron desde tierras chaqueñas bolivianas durante siglos, siendo la del último siglo XX la más contemporánea, conformando núcleos bastantes numerosos, establecidos ya desde el siglo XIX y fundamentalmente, luego de la Guerra del Chaco. $\mathrm{Si}$ bien existen fronteras étnicas/lingüísticas entre los llamados chiriguanos o actuales guaraníes, las mismas no están definidas territorialmente, aunque es posible señalar un predominio de los ava guaraní, hablantes en el área de frontera argentina-boliviana (Combès 2005:20). Ya ha sido estudiada, por Isabel Combès (2005), la relación histórica establecida entre las etnias chané, izoseños y ava guaraní, para el actual territorio boliviano, no así para el lado argentino. Sin embargo, podemos deducir, a partir de sus análisis, que muchas de las familias que viven en comunidades a la orilla de la ruta nacional 34, provienen de la zona del Izoso (Bolivia). De acuerdo a estos estudios etnohistóricos ${ }^{1}$, esta región posee un marcado sello chané, aunque las comunidades que allí habitan no se reconocen como tales ni hablan la lengua chané (del tronco arawak), sino que emplean una variación del ava guaraní (del tronco tupi guaraní).

Dentro del territorio boliviano se dio un proceso de reconfiguración étnica, en el cual los izoseños devinieron con el tiempo en "guaraníes", olvidando su herencia chané (Combés, 2005:314). Estos procesos de etnogénesis van acompañados de una fuerte guaranización lingüística. En cambio en Argentina, el pueblo Chané ha realizado un proceso diferente, cuenta con el reconocimiento oficial del Estado Nacional y reconoce una cultura y lengua propia, aunque se saben emparentados con los guaraníes. Los izoseños y los chané de Argentina, si bien están parcialmente guaranizados, mantienen sus fronteras étnicas con los chiriguanos o guaraníes (Bolivia), llamados ava guaraní en Argentina (Casimiro Córdoba y Flores, 2017).

Sea guaraní (izoseño, ava, simba) o chané, paye o ipaye, son los términos utilizados entre ellos para designar a los "mediadores entre el mundo 
terrenal y el mundo espiritual [que] tienen el poder de diagnosticar enfermedades, curar, apoyar y guiar espiritualmente a las personas" (Hirsch, Huenuan y Soria, 2015:23). Como se observa en esta definición, la función de promotor de salud indígena tradicional parece aunar no solamente las curas físicas, sino también, a las espirituales.

El tema de la espiritualidad del chamanismo guaraní y chané, se puede asociar con 'lo psicológico', suponiendo que ese "mundo espiritual", y los seres que lo habitan, actúan en la construcción de la personalidad y la subjetividad guaraní. A partir del estudio de los análisis planteados por los diferentes autores citados en el artículo, se puede pensar que las prácticas y funciones del ipaye están basadas en procesos de cristianización de su espiritualidad tradicional:

\footnotetext{
"El ipaye, a través de diferentes técnicas como el uso del cigarrillo, cantos o rezos, plantas medicinales y sueños, logra identificar las causas de la enfermedad y restablecer la salud del paciente. A partir de los procesos de evangelización católica y evangélica, ha disminuido la creencia y la presencia del ipaye entre los miembros de las comunidades guaraní y chané, pero aun así muchas personas siguen confiando en sus poderes curativos y su capacidad para erradicar la enfermedad".(Hirsch, Huenuan y Soria, 2015:23).
}

Con esta afirmación, los autores se plantean, en la misma línea de análisis y con mayor profundidad, cuáles son esas múltiples facetas del chamanismo guaraní-chané, y como son las relaciones entre este y el cristianismo (católico y evangélico).

Muchos casos estudiados muestran que, la iniciación al chamanismo, entre los grupos indígenas chaqueños (wichi, chulupí, toba, guaraní), se produce a partir del contacto de una persona con entidades o alteridades poderosas que le otorgan el poder de cura, o a través de la enseñanza personalizada de un maestro espiritual (Wright, 2008). Los estudios sobre chamanismo guaraní consideran a los payes como practicantes de la medicina tradicional, pero poco han tenido en cuenta las relaciones inter-substanciales con otras especies y alteridades con las cuales conviven. Si bien, los sistemas chamánicos amerindios y sus prácticas son complejas y diversas, las particularidades de los ipayereta guaraní se manifiestan en el uso de determinadas técnicas para mediar con las fuerzas espirituales (no humanas) que operan en sus sistemas cosmopolíticos. Pues estos payes acceden a "otros mundos" y a la adquisición del "poder de cura", ya sea a través del consumo de plantas y sustancias específicas, o través de los sueños y de técnicas corporales para evocar sus experiencias chamánicas (Riester, 1998, Idogaya Molina, 1978).

\section{MEDIACIONES ESPIRITUALES: LOS GUARANÍ Y LOS CHANÉ EN EL AHORA}

La figura del paye se reconfigura en la actualidad a partir de la categoría de médico tradicional. Esta categoría, si bien impone una legitimidad enmarcada en la medicina occidental, se la utiliza para no manifestar la condición de paye que algunas personas poseen, legitimando sus prácticas en el uso $\mathrm{y}$ conocimiento de plantas medicinales. Solo en una relación de confianza, los médicos tradicionales que son a su vez payes, pueden manifestar su trabajo completo, pues los que son paye lo ocultan a la mirada occidental. Esto debido a los procesos de evangelización que han permeado las prácticas de los payes guaraní y chané, siendo muchos de ellos profesantes del evangelismo y del catolicismo. 
En el trabajo etnográfico que se viene realizando desde el año 2015 al 2019, se ha corroborado que los sistemas chamánicos guaraní/chané y los saberes locales, están yuxtapuestos a los sistemas de creencias cristianas. Algunos de los médicos tradicionales guaraní y chané, que se han convertido al evangelio, no dejaron de practicar sus rituales de curación a partir del secreto y en dialogo con los diferentes iyas o seres de la naturaleza.

El trabajo etnográfico se realizó en comunidades que se auto reconocen como guaraníes y chané en el norte de Argentino, pero donde viven en plurietnicidad con familias chané, izoseñas, simbas, ava y tapietes, conviviendo en estos espacios. De hecho, los matrimonios interétnicos son muy comunes y sobrepasan los límites étnicos, habiendo matrimonios con criollos y extranjeros (europeos).

Durante las etnografías en comunidades guaraníes y chané, se ha intercambiado experiencias con cinco médicos tradicionales, de los cuales tres son payes. Cuatro de ellos son evangélicos, mientras que uno es católico.

\begin{tabular}{|c|c|c|c|}
\hline Médicos guaraní chané & Saberes locales & $\begin{array}{c}\text { Espiritualidad y } \\
\text { religion }\end{array}$ & Cargo en comunidad \\
\hline Medico tradicional 1 & Ex paye & evangélico & cacique \\
\hline Medico tradicional 2 & Paye & evangélico & mburuvicha \\
\hline Medico tradicional 3 & Saber sobre plantas & evangélico & mburuvicha \\
\hline Medico tradicional 4 & Saber sobre plantas & católico & mburuvicha \\
\hline Medico tradicional 5 & Ex paye & evangélico & cacique \\
\hline
\end{tabular}

Este cuadro de cruces de roles permite visualizar las articulaciones religiosas, políticas y étnicas entre los médicos tradicionales. El análisis de estos aspectos desentrama la etnopolítica indígena guaraní chané, que expresa prácticas y saberes locales. En este sentido, el liderazgo debe ser analizado articuladamente con las prácticas religiosas y chamánicas.

Como se aprecia en el cuadro anterior, la transfiguración de la figura del paye a médico tradicional, es producto del proceso de evangelización, donde los ex payes adquieren nuevas nociones para la organización de su trabajo de cura física y espiritual. Por otro lado, el aspecto político también está presente dentro de los roles religiosos que tienen los médicos tradicionales en sus comunidades. Ellos detentan ciertos privilegios de status intra e intercomunitarios para el reconocimiento de sus saberes. Tanto los que solo manejan plantas como aquellos que todavía manejan poderes mágicos con la cura por secreto y la alianza con distintos tipos de seres espirituales, son muy solicitados en sus comunidades, e inclusive tienen una agenda de acciones conjuntas con otras autoridades comunitarias, es decir que, ninguno de ellos solo se dedica a ser médico tradicional, sino que cumple funciones importantes dentro de sus comunidades.

Los médicos tradicionales también demuestran tener ese conocimiento que se adjudica a los payes, el saber hacer en dialogo con los seres espirituales, aunque parece que en diferentes niveles de conocimiento. Los secretos y las formas de hacer los ritos manifiestan el nivel de conocimiento que maneja el médico tradicional. Lo que todos reconocen es que, la naturaleza tiene una agencia social dentro del mundo que comparten. Por ejemplo, en palabras de uno de los médicos, "los arboles saben lo que necesitamos, por eso cuando usas sus hojas o corteza le tenes que pedir permiso, no al árbol en si, sino al espíritu del árbol" (médico tradicional 2), de esta manera funciona su carácter medicinal, un poco a través de pedir permiso, y un poco peticionando la cura. 
Así, los remedios naturales basados en plantas medicinales con los que trabajan los médicos tradicionales, están mediados por peticiones o rezos a los seres espirituales, lo que garantiza una cura por secreto. Cuando encuentran un árbol que es verdaderamente poderoso y sanador, ellos lo mantienen y lo cuidan, se sientan y hablan con él, le explican que lo necesitan para curar, le hacen ofrendas y promesas. De igual manera cuando van a utilizar las hojas o corteza, no maltratan al árbol, sino que lo tratan con mucha delicadeza para no hacerles daño.

Todos ellos tienen que estar en armonía con el principal ser espiritual para el paye y para el pastor, es el dueño de la palabra o el ser espiritual que te confiere el poder de la palabra. Tanto la palabra del médico tradicional dirigiéndose al árbol como la del pastor dirigiéndose a Jehová, es sagrada en el sentido de que en ella se manifiesta un ser espiritual. Así, el médico tradicional y el pastor se convierten en medidores espirituales.

Por otro lado, los médicos tradicionales que se han convertido al evangelio, muchas veces niegan sus poderes o saberes mágicos religiosos, dado a que en este dogma el chamanismo esta sentenciado como pecado. Sin embargo, no vemos que sea una contradicción al interior de la vida de cada uno de ellos, al contrario, vemos que se asumen y no se niegan en la intimidad de las familias. Por otro lado, se ha notado que en esferas publicas prevalece el estatus de creyente o la identificación con el evangelio, dejando a un lado la de mediador y sanador.

Sin embargo, más allá de la adscripción religiosa, los médicos tradicionales cumplen un rol en sus comunidades y hacen pactos con los seres de las plantas y animales del monte. Respetan y hacen agradecimientos después que los pacientes sanan, si no vuelven a la fuente u origen de la cura, que es el propio monte con sus seres espirituales, la práctica de cura no tiene su efecto ritual. Esto esta naturalizado entre los médicos tradicionales, porque ellos son parte de ese monte, es "lo natural" para ellos, más allá de su evangelización.

\section{A MODO DE CIERRE}

En este articulo se analizaron algunos de los cambios generados en la espiritualidad guaraní tradicional tras el contacto intercultural con el cristianismo católico y evangélico. Se vio como la figura del paye se fue transfigurando, pero no dejo de tener un rol político en las nuevas reconfiguraciones identitarias de los guaraní y chané.

En las etnografías presentadas como estudios de casos, se ve que las variantes del cristianismo se asientan junto al chamanismo en las comunidades indígenas donde realizamos nuestro trabajo de campo. Entre los indígenas guaraníes del umbral Chaco salteño, se configuran realidades y situaciones heterogéneas, con respuestas localizadas y diferenciadas a los problemas de salud y cura de enfermedades.

Las prácticas chamánicas están asociadas y yuxtapuestas a las configuraciones evangélicas y católicas, y moldeadas en el paradigma de la medicina occidental, lo que muestra el carácter heterodoxo del paye o ex paye en relación a los aspectos etnopolíticos y al liderazgo al interior de las comunidades.

En este sentido, este sistema chamánico fue reconfigurándose, no solo adaptándose a las necesidades de salud y de cura, sino también, manteniendo su carácter etnopolítico en la actualidad. Es así que encontramos en el trabajo de campo, que las lógicas de estos grupos, tal como lo afirma Bartolomé, 
exhiben una plasticidad y una gran capacidad adaptativa (Bartolomé, 2008). La reconfiguración de los guaraní y chané representa la transfiguración de una colectividad cultural y lingüística a partir del desarrollo de un culto milenarista cristiano y una doctrina salvacionista, liderados por los chamanes (De Rose y Langdon, 2013:18).

No cabe duda que el rol político de los médicos tradicionales es parte de un desdoblamiento de una transfiguración más amplia, donde la figura del chaman se reconfigura en escenarios de nuevas espiritualidades en las comunidades indígenas contemporáneas. En este trabajo traemos a colación del debate sobre la agencia de los payes y el desarrollo de estrategias identitarias, que permiten mantener y transmitir el conocimiento y reconfigurar la espiritualidad indigena.

\section{NOTAS}

${ }^{1}$ Etnógrafos como Eric Van Rosen, Ernald Nordeskiold, Alfred Metraux, y sacerdotes como fray Mingo de la Concepción, Bernardino de Nino, Alejandro Corrado, Antonio Comajuncosa, etnohistoriadores como Isabel Combés y Thierry Saignes entre otros.

\section{BIBLIOGRAFÍA}

BARTOLOME, Miguel. “Oguerojera (desplegarse). La etnogénesis del pueblo Mbya guaraní”. Ilha 10 (1): 105-140, 2008.

BOSSERT, Federico. Las almas de los muertos entre los Chané”. Dissertação (X Jornadas sobre Alternativas Religiosas en Latinoamérica) - Facultad de Ciencias Sociales, Universidad de Buenos Aires, 2000.

CASIMIRO CÓRBOBA, Ana V.; FLORES Maria Eugenia. El maestro bilingüe guaraní. Escuela, estado y pueblos originarios. Inédito, 2017.

CENTURIÓN MENELES, Hugo Florencio. Observaciones sobre chamanismo y el rito del bautismo entre los Ava-Katu-Ete. Cadernos do LEPAARQ - Textos de Antropologia, Arqueologia e Patrimônio, v. X, n. 19, p.121-137, 2013.

COMBÈS, Isabel. Etnohistorias del Izoso Chané y chiriguanos en el Chaco Boliviano (S. XVI y XX). La Paz Bolivia: PIEB y IFEA, 2005.

ESPINOZA, Mariana. Fragmentos "más o menos guaraníes" de una visión evangelica en el Ingenio La Esperanza. In: CERIANI CERNADAS, César (Ed.). Los evangelios chaqueños. Misiones y estrategias indígenas en el siglo XX. Buenos Aires: Asociación Civil Rumbo Sur, 2017.

FLORES, María Eugenia. La coca y los modos de hacer: Una aproximación etnográfica a la agencia de la planta en terapias y rituales populares de Salta. Dissertacion. (Doctorado en Antropología) Departamento de Posgrado Facultad de Filosofía y Letras, Universidad de Buenos Aires, 2017.

HIRSCH, Silvia; HUENUAN, Catalina; SORIA, Marcelo. Guaraníes, chanés y tapietes del norte argentino. In: Ministerio de Educación de la Nación (Tomo 2). Pueblos Indígenas en Argentina. Historias, culturas, lenguas y educación,Ciudad Autónoma de Buenos Aires: Ministerio de Educación y Deportes de la Nación, 2016.

IDOYAGA MOLINA, Anatilde. Shamanismo Chiriguano. Cuadernos Franciscanos, nro. 49, Los grupos aborígenes del límite occidental del Gran Chaco. Salta: Convento San Francisco, 1978.

METRAUX, Alfred. Migraciones Historicas de los Tupi-Guarani.Chaco: Resistencia, 1974. 
METRAUAlfred. Le Shamanism chez les Indiens de l'Amérique du Sud Tropicale. Acta Americana, vol. II, p. 195-219,1944.

PEREZ BUGALLO, Nahuel. Memorias de la Misión de Altolozano: guaraníes y franciscanos en el Ingenio San Martín del Tabacal 1938-1970. In: CERIANI CERNADAS, César (Ed.). Los evangelios chaqueños. Misiones y estrategias indígenas en el siglo XX. Buenos Aires: Asociación Civil Rumbo Sur, 2017.

PRITCHARD, Evans. Brujería, magia y oráculos entre los azande. Barcelona: Anagrama, 1976.

RENARD CASEVITZ, FM; SAIGNES, T; TAYLOR AC.Al este de los Andes. Relaciones entre las sociedades amazónicas y andinas entre los siglos XV y XVII. Perú: Abya Yala, 1988.

ROSSO, Cintia. Los "hechiceros" guaycurúes en el Gran Chaco durante el siglo XVIII. Maguaré, v. 26, n. 1, p. 161-194, enero, 2012.

RIESTER, Juergen. Aspectos del chamanismo de los Izoseño guaraní.Suplemento Antropológico Revista del centro de estudios antropológicos, vol. XXI, n. 1, p. 263-283, 1986.

RIESTER, Juergen. El Gran Fumar, chamanismo guaraní. Bolivia: Santa Cruz de la Sierra, 1998.

SAIGNES, Thierry. Historia del pueblo chiriguano. Bolivia: Plural, 2007.

SANTANA DE ROSE, Isabel y LANGDON Esther. Chamanisco guaraní contemporáneos en Brasil: un estudio de transfiguración cultural. Revista Colombiana de Antropologia, v. 49 (1): 105-127, 2013.

VILLAR, Diego. Religiones omnívoras: el chamanismo chané y las relaciones interétnicas. Anthropologica, año xxv, n 25, pp. 157-170,2007.

VILLAR, Diego. La religión del monte entre los Chané. Suplemento Antropológico, vol. xlvi, n 1, p.151-202,2011.

VILLAVICENCIO MATIENZO, Víctor Rene. La narrativa guaraní-chiriguano: una aproximación hermenéutica. Dissertação. (Doctorado em Filosofía) Universidad Complutense de Madrid, Facultad de Filosofía Departamento de Filosofía del derecho, 2007.

WRIGHT Pablo. Ser en el sueño: crónicas e historias de vida toba. Buenos Aires: Biblos, 2008. 